\title{
Macular blood flow velocity in sickle cell disease: relation to red cell density
}

\author{
Monique S Roy, Pedro Gascon, Danny Giuliani
}

\begin{abstract}
Aims/Background-While the retinal lesions of sickle cell retinopathy have been well documented, their pathogenesis remains unclear. The purpose of this study was (1) to compare macular blood flow velocity in patients with sickle cell disease and controls, and (2) to determine in sickle cell patients the relation between macular blood flow velocity and red blood cell density.

Methods-Macular blood flow velocity was measured in 18 patients with stable sickle cell disease and 45 normal controls using blue field entoptoscopy. Red blood cell density was determined by the phthalate ester density method.

Results-There were no significant differences between patients and controls for leucocyte velocity. However, in the sickle cell patients leucocyte velocity in the macular capillaries was significantly negatively associated with greater range of red blood cell density $(p<0.002$ and $p<0.04$ for right and left eyes, respectively).

Conclusion-These results suggest that in sickle cell patients heterogeneity of the density of the red blood cells may slow down macular capillary blood flow. (Br f Ophthalmol 1995; 79: 742-745)
\end{abstract}

Patients with sickle cell disease may have retinal signs ranging from the mild peripheral signs of retinal vascular occlusion to the more severe form of proliferative sickle cell retinopathy (PSR) with visual loss. ${ }^{1-4}$ To date, studies examining haematological factors in relation to the severity of sickle cell retinopathy have yielded negative or conflicting results. ${ }^{5-7}$ However, retinal arteriolar occlusion has been well documented in sickle cell retinopathy, ${ }^{2} 8$ although the exact location of the initial obstructive event and its pathogenesis remain unclear. ${ }^{9}$ Goldberg ${ }^{8}$ has suggested that intravascular red blood cell sickling and increased blood viscosity may be the cause of this vascular occlusion.

An alternative hypothesis has been proposed by Noguchi and Schechter, ${ }^{10}$ who have shown that most red blood cells of sickle cell patients have a high concentration in polymerised haemoglobin S, even at arteriolar oxygen saturation concentrations. This results in a large population of poorly deformable red blood cells in the circulation. Schechter et al ${ }^{1112}$ have hypothesised that in sickle cell patients these poorly deformable red blood cells become blocked in arterioles, in particular at the level of the precapillary sphincter.
Red blood cell haemoglobin concentration and density can be quantified using the calibrated phthalate ester technique. ${ }^{13}$ In this technique, venous blood mixed with solutions of dimethyl phthalate and n-butyl phthalate ranging in specific gravities from 1.060 to 1.136 (with increments of 0.004 ) is loaded in microcapillary tubes and centrifuged. The ratio of the height of packed red blood cells below the ester layer to the total height of the blood column (measured in $\mathrm{mm}$ ) is used to quantify the relative distribution of erythrocyte densities. In normal subjects the range of densities within which the middle $60 \%$ of the red blood cell population is distributed (R60 values) is 0.0068 (SD 0.0009). ${ }^{13}$ Using this technique, we have previously shown that in sickle cell patients R60 values are significantly associated with the severity of the conjunctival 'comma' sign. ${ }^{14}$ In the present study, we hypothesised that in sickle cell patients blood flow velocity in the retinal vessels of the macular region would be significantly negatively associated with increased heterogeneity of the density of red blood cells.

Thus, the purpose of the present study was to measure macular blood flow in patients with sickle cell disease in order to determine (1) whether its velocity, as measured by the blue field entoptoscope, is decreased when compared with age and sex-matched normal subjects and (2) whether such a decrease is associated with the extent of red blood cell heterogeneity - that is, the distribution in intracellular haemoglobin concentration or R60 values as measured with the phthalate ester separation technique.

\section{Subjects and methods}

We studied a consecutive series of 18 patients, 12 women and six men, with stable sickle cell disease, sickle cell anaemia in 12, and sickle cell disease in six. Their mean age was 31.4 (12) years. The diagnosis of sickle cell disease was made on the basis of red blood cell haemoglobin electrophoresis. No patient was included who either had a sickle cell crisis during the previous month, or had had a blood transfusion in the previous 4 months, or was receiving long term medication other than folic acid.

Biomicroscopy of the anterior segment and a detailed examination of the retina by direct and indirect ophthalmoscopy, and using a Goldmann 3 mirror contact lens, were performed. Retinal findings in each quadrant were recorded on a fundus drawing. Severity of the sickle cell retinopathy was graded using Goldberg's classification. ${ }^{2}$ Severity of the conjunctival comma sign was graded as mild, if 


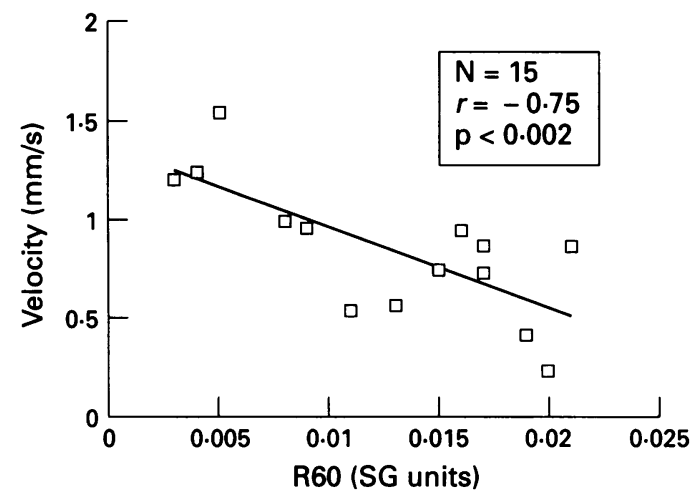

Figure 1 Leucocyte velocity in the right eyes of patients with sickle cell disease was significantly negatively associated with the range of density of the $60 \%$ of the red blood cell population (R60 values) $(p<0.002)$.

$\leqslant 10$ commas and as moderate to severe, if $>10$ commas were seen on slit-lamp examination.

Haematological tests were performed on the day of the examination by one of us (DG), who was unaware of the clinical findings. Red blood cell density profile was determined by the calibrated phthalate ester density method. ${ }^{13}$ The middle $60 \%$ density range (R60), the range of densities within which $60 \%$ of the red blood cell population is distributed, was calculated. ${ }^{13}$ Other haematological tests included total haemoglobin levels, mean red cell corpuscular haemoglobin concentration (MCHC), reticulocyte count, and the fraction of fetal haemoglobin $(\mathrm{HbF})$.

Forty five not previously tested normal subjects, 23 women and 22 men, served as controls. Their mean age was $34 \cdot 2(11 \cdot 2)$ years. They all had a normal eye examination, were on no medication, and has no systemic disease. They had normal haemoglobin electrophoresis.

Patients and controls were seated in a dimly lit room in front of a blue field entoptoscope (Oculix 1000, Beryn, PA, USA) without prior pupillary dilatation or dark adaptation. The entoptoscope provided diffuse uniform Maxwellian illumination of the retina at a wavelength of $430 \mathrm{~nm}$. The patient looking in the centre of the field visualised his own leucocytes flowing in the macular capillaries.

The subject's matching accuracy was determined by having him or her adjust the particle density and velocity on an adjustable stimulation test screen, and only subjects with an accuracy of $80 \%$ or greater were included. Subjects were then instructed to adjust the density and velocity of the computer stimulated leucocytes to match those of their own entoptically perceived leucocytes. The cycle of pulsatile velocity matched that of the subject's heart rate measured by means of a finger pulse transducer. The pulsatility remained fixed. The starting value of the simulation particle density and velocity was randomised for each trial. Three trials were completed and the averages of leucocyte density and velocity of the three trials were calculated. Each eye was tested separately, always starting with the right eye. Informed consent was obtained from all subjects after the nature of the procedure had been fully explained.
In the statistical analysis, Student's $t$ test was used. Association of leucocyte velocity and haematological variables was tested with Pearson's method of correlation and various covariates were adjusted for with stepwise multiple regression analysis. ${ }^{15} 16$ All $\mathrm{p}$ values were two tailed.

\section{Results}

LEUCOCYTE VELOCITY AND RED BLOOD CELL DENSITY (R60 VALUES)

There was a significant negative association between leucocyte velocity in the macular capillaries of sickle cell patients and heterogeneity of the red blood cell population density as assessed by $\mathrm{R} 60$ values (for right eyes, $r=-0.75, \mathrm{~N}=15, \mathrm{p}<0.002$, and for left eyes, $r=-0.55, \mathrm{~N}=14, \mathrm{p}<0.04$ ) (Figs 1 and 2). Although leucocyte velocity in the right eyes of sickle cell patients was significantly lower than in the left eyes $(0.84(0.34) \mathrm{mm} / \mathrm{s} v 0.94(0.32)$ $\mathrm{mm} / \mathrm{s}, t=2.92, \mathrm{p}<0.05)$, values for right and left eyes were significantly correlated $(r=0 \cdot 78$, $\mathrm{N}=14, \mathrm{p}<0.01$ ).

Sickle cell patients had a mean haemoglobin value of $8.9(2.3) \mathrm{g} / \mathrm{dl}$ and mean corpuscular haemoglobin concentration of $34 \cdot 1 \%(1 \cdot 0 \%)$. Since anaemia might also influence blood flow velocity, we examined leucocyte velocity in relation to both R60 and haemoglobin values by multivariate stepwise analysis. When both of these variables were entered in the analysis, R60 was the only haematological variable significantly negatively associated with leucocyte velocity $(p=0.004$ and $p=0.05$ for right and left eyes, respectively).

\section{LEUCOCYTE VELOCITY AND DENSITY IN SICKLE} CELL PATIENTS AND CONTROLS

There was no significant difference between patients and controls for either leucocyte velocity (for right eyes, $0.84(0.34) \mathrm{mm} / \mathrm{s} v$ $0.78(0.23) \mathrm{mm} / \mathrm{s}, t=0.62, \mathrm{df}=61, \mathrm{NS}$, and for left eyes, $0.94(0.32) \mathrm{mm} / \mathrm{s} v 0.86(0.25)$ $\mathrm{mm} / \mathrm{s}, t=0 \cdot 85, \mathrm{df}=59, \mathrm{NS})$, or for leucocyte density (for right eyes, 85 (78) v 105 (71), $t=0.82, \mathrm{df}=61$, NS, and for left eyes, $127(107) v 108(68), t=0 \cdot 83, \mathrm{df}=59, \mathrm{NS})$ (Fig 3).

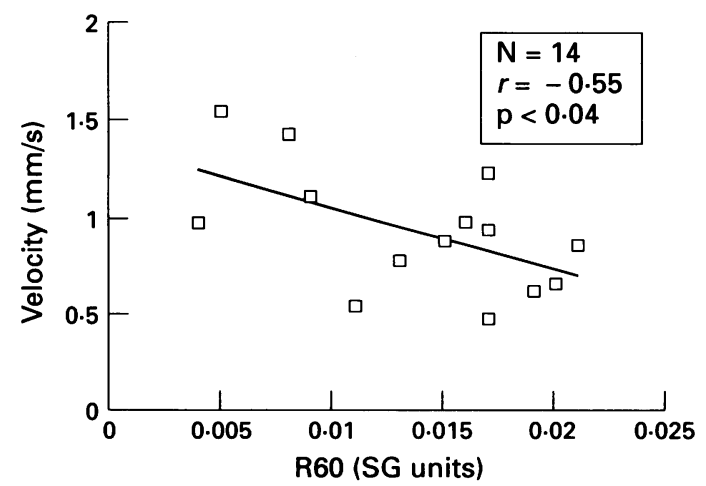

Figure 2 Leucocyte velocity in the left eyes of patients with sickle cell disease was significantly negatively associated with $R 60$ values $(p<0 \cdot 04)$. 


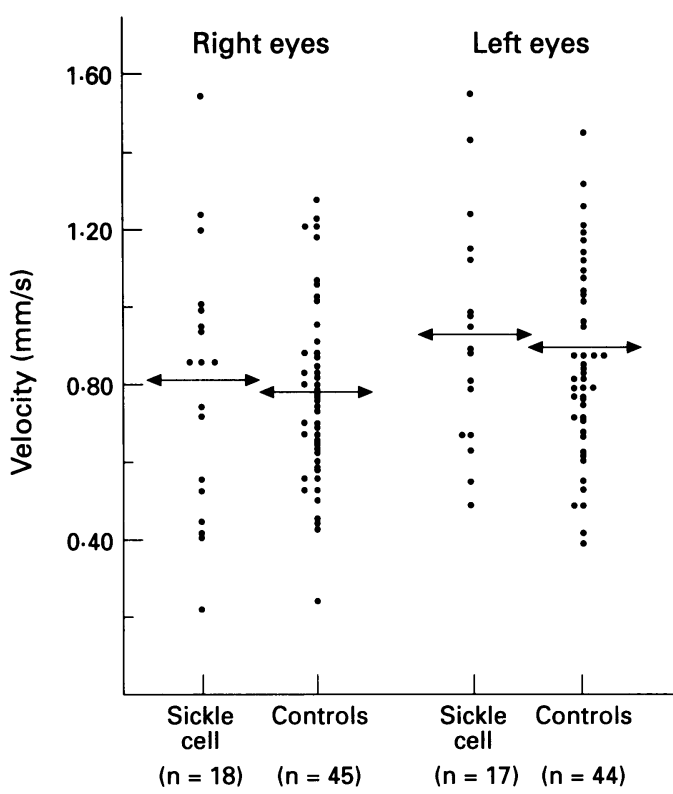

Figure 3 There were no significant differences between sickle cell patients and normal subjects for leucocyte velocity for either right eyes $(0.84(0.34) \mathrm{mm} / \mathrm{s})$ v $0.78(0.23)$ $\mathrm{mm} / \mathrm{s}, \mathrm{t}=0.62, \mathrm{df}=61, \mathrm{NS})$ or left eyes $(0.94(0.32) \mathrm{mm} / \mathrm{s}$ v $0.86(0.25) \mathrm{mm} / \mathrm{s}, \mathrm{t}=0.85, d f=59, \mathrm{NS})$.

\section{Discussion}

In the present study, we found that leucocyte velocity in the macular capillaries of patients with sickle cell disease, as measured by blue field entoptoscopy, was significantly and negatively associated with wider density range of the red blood cells or R60 values. However, there were no significant differences for either leucocyte velocity or density between patients and normal controls.

The blue field simulation technique allows measurement of leucocyte velocity in the macular capillaries. ${ }^{17} 18$ While such measurements are subjective, reproducibility studies have shown that the blue field entoptic technique is reliable. ${ }^{19}$ In the present study, only subjects who matched the simulation with $80 \%$ accuracy were included. Also, the examiner involved in the blue field entoptic measurements was not aware of the blood results. In the present study, leucocyte velocity in normal subjects was similar to that reported by Riva, ${ }^{17}$ but higher than that reported by Kohner using a different instrument. ${ }^{19}$ Among sickle cell patients leucocyte velocity was lower in right compared with left eyes (although velocity values for right and left eyes were strongly correlated). This may explain the difference between right and left eyes in the significance level of the relation of velocity and $\mathrm{R} 60$ values.

It has been shown previously that in small calibre capillaries, such as those in the macula, the speed of the leucocytes is equal to the mean speed of the bulk flow and proportional to the speed of the red blood cells. ${ }^{20}$ This assumes that the capillary diameter remains constant. While this may be the case in normal macular capillaries, ${ }^{21} 22$ we do not know whether this applies to our patients since we have not measured retinal blood vessel diameter.

The absence of significant differences for leucocyte velocity between patients and controls may be due to a lack of sensitivity of the method, as reflected in the wide range of leucocyte velocity values among normal subjects. It may also indicate autoregulation of the macular capillary blood flow ${ }^{2324}$ to protect the macula at the expense of the peripheral retina. Also, measurement of retinal blood flow in the macular capillaries may not be representative of all capillaries in the retina, particularly in sickle cell patients in whom lesions of sickle cell retinopathy are seen primarily in the peripheral retina. However, blood flow measurement in the small vessels of the retinal periphery is technically difficult.

In sickle cell patients, the irreversibly sickled red blood cell (ISC), because it is permanently stiff and deformed, has long been considered as a likely candidate for initiation of occlusion. For instance, the percentage of ISCs has been found to correlate with severity of the conjunctival comma sign. ${ }^{15}$ However, no clear relation has been demonstrated between ISCs and clinical occlusive manifestations, such as pain crises or the lesions of sickle cell retinopathy. This may be because ISCs represent only a small fraction of circulating red blood cells and their quantification in the laboratory is technically difficult. Also, sickling is likely to occur where oxygen saturation is lowest - that is, either on the venular end of the capillary or the venule itself. This is not consistent with the clinical observation that occlusion of small retinal arterioles, particularly in the retinal periphery, is an early sign of sickle cell retinopathy. ${ }^{2}$

The results of the present study suggest that in sickle cell patients high R60 values - that is, the heterogeneity of density of the red blood cells, may play a role in slowing down retinal blood flow. After intravenous injection of fluorescein, sickle cell patients consistently show persistence of the dye particularly in the peripheral retinal capillaries long after the injection of the dye, suggesting that the retinal blood circulation is slowed down. Our results in sickle cell patients are comparable with those reported in patients with background diabetic retinopathy, in whom decreased leucocyte velocity compared with normal subjects has been attributed to red blood cell decreased deformability. ${ }^{25}$ In the present study, we have not measured blood viscosity, although viscosity might be another factor involved in slowing down retinal blood flow in sickle cell patients.

In summary, the results of the present study indicate that macular blood flow velocity as determined by blue field entoptoscopy is significantly negatively associated with red blood cell density in patients with sickle cell disease. Longitudinal studies of sickle cell patients are needed to further elucidate the role of red blood cell density in the pathogenesis of sickle cell retinopathy.

Thanks are due to Richard Bach, Timothy Brabston for technical assistance and to Maxine Wanner and Rick Press for the photographs.

1 Welch RB, Goldberg MF. Sickle cell hemoglobin and its relation to fundus abnormality. Arch Ophthalmol 1966; 75: 353-62.

2 Goldberg MF. Classification and pathogenesis of proliferative sickle retinopathy. Am $\mathcal{f}$ Ophthalmol 1971; 71: 649-65. 
3 Condon PI, Serjeant GR. Ocular findings in homozygous sickle cell anemia in Jamaica. Am $\mathcal{F}$ Ophthalmol 1972; 73 533-43.

4 Condon P, Serieant GR. Behaviour of untreated proliferative sickle cell retinopathy. $\mathrm{Br} \mathcal{F}$ Ophthalmol 1980; 64: 404-11.

5 Hayes RJ, Condon PI, Serjeant GR. Hematological factors associated with proliferative retinopathy in homozygous sickle cell disease. Br f Ophthalmol 1981; 65: 29-35.

6 Talbot JF, Bird AC, Rabb LM, Maude GH, Serjeant GR Sickle cell retinopathy in Jamaican children: a search for Sickle cell retinopathy in Jamaican children: a search

7 Serjeant BE, Mason KP, Acheson RW, Maude GH, Stuart J, Serjeant GR. Blood rheology and proliferative retinopathy in homozygous sickle cell disease. $\mathrm{Br} \mathcal{F}$ Ophthalmol 1986; 70: 522-5.

8 Goldberg MF. Retinal vasoocclusion in sickling hemoglobinopathies. Birth Defects 1976; 12: 475-515.

9 Romayananda N, Goldberg MF, Green RW. Histopathology of sickle cell retinopathy. Trans Am Acad Ophthalmol Otolarymgol 1973; 77: 652-76.

10 Noguchi CT, Schechter AN. The intracellular polymerization of sickle hemoglobin and its relevance to sickle cell disease. Blood 1981; 58: 1057-68.

11 Brittenham GM, Schechter AN, Noguchi CT. Hemoglobin $S$ polymerization: primary determinant of the hemolytic and clinical severity of the sickling syndromes. Blood 1985; 65: 183-9.

12 Schechter AN, Noguchi CT, Rodgers GP. Sickle cell anemia. In: Stamatoyannopoulos G, Nienhuis AW, Leder $P$ Majerues PW, eds. The molecular basis of blood diseases. Philadelphia: WB Saunders, 1987: 179-218.

13 Rodgers GP, Schechter AN, Noguchi CT. Cell heterogeneity in sickle cell disease: quantitation of the erythrocyte density profile. $\mathcal{F}$ Lab Clin Med 1985; 106: 30-7.
14 Roy MS, Rodgers GP, Podgor MJ, Noguchi CT, Nienhuis AW, Schechter AN. Conjunctival sign in sickle cell anemia: as in vivo correlate of the extent of red cell heterogeneity. Br $\mathcal{F}$ Ophthalmol 1985; 69: 629-32.

15 Snedecor GW, Cochran WG. Statistical methods. Ames, IA: Iowa State University, 1980

16 Dixon WJ, ed. BMDP statistical software. Berkeley: University of California Press, 1983.

17 Riva CE, Petrig B. Blue field entoptic phenomenon and blood velocity in the retinal capillaries. 7 Optom Soc Am blood velocity in

18 Sinclair SH, Azar-Cavanagh M, Soper KA, Tuma RF, Mayrovitz HN. Investigation of the source of the blue field entoptic phenomenon. Invest Ophthalmol Vis Sci 1989; 30: 668-73.

19 Fallon TJ, Chowiencyzk P, Kohner EM. Measurement of retinal blood flow in diabetes by the blue light entoptic phenomenon. Br 7 Ophthalmol 1986; 70: 43-6.

20 Schmid-Schoenhein GW, Skalak R, Usami S, Chein S. Cell distribution in capillary networks. Microvasc Res 1980; 19: 18-44.

21 Friedman E, Smith TR, Kuwabara T. Retinal microcirculation in vivo. Invest Ophthalmol 1964; 3: 217-26.

22 Baez S, Lamport H, Baez A. Pressure effects in living microscopic vessels. In: Copley AL, Staisby G, eds. Flow proper ties of blood. London: Pergamon Press, 1960: 122-36. 23 Riva CE, Loebl M. Autoregulation of blood flow in the cap-
illaries of the human macula. Invest Ophthalmol 1977; 16: 568-71.

24 Riva CE, Sinclair SH, Grunwald JE. Autoregulation of retinal circulation in response to decrease of perfusion pressure. Invest Ophthalmol Vis Sci 1981; 21: 34-8.

25 Rimmer T, Fallon TJ, Kohner EM. Long-term follow-up of retinal blood flow in diabetes using the blue light entoptic phenomenon. Br f Ophthalmol 1989; 70: 1-5. 